\title{
PAISAJES INDUSTRIALES E INDUSTRIAS PARA EL TURISMO: SIMBOLISMO PATRIMONIAL Y ALCANCE TERRITORIAL
}

\author{
Carlos J. Pardo Abad \\ Departamento de Geografía \\ Universidad Nacional de Educación a Distancia (UNED)
}

\begin{abstract}
Resumen: El concepto de turismo industrial explica un fenómeno emergente referido a las prácticas turísticas surgidas en torno a las industrias aún en activo, con visitas que pretenden aproximar al visitante a los procesos técnicos de producción, o a los lugares de tradición histórica con instalaciones que abandonaron hace tiempo la actividad y se han reabierto para el turismo. En ambos casos la experiencia personal de visita gira en torno a las tecnologías y el saber hacer, los edificios y los lugares industriales, las etapas económicas y sociales y la estética que crea la industrialización o la pérdida definitiva de la producción. Los territorios juegan un papel muy importante por ser el marco de las distintas fases de la Revolución Industrial, con las sucesivas transformaciones y declives, que generan vestigios e hitos patrimoniales que son testigos directos de un importante legado material.
\end{abstract}

Palabras clave: Turismo, industria, patrimonio industrial, territorio, paisaje.

Resumo: Paisaxes industriais e industrias para o turismo: simbolismo patrimonial e alcance territorial

O concepto de turismo industrial explica un fenómeno emerxente referido ás prácticas turísticas xurdidas ao redor das industrias aínda en activo, con visitas que pretenden aproximar o visitante aos procesos técnicos de produción, ou aos lugares de tradición histórica con instalacións que abandonaron hai tempo a actividade e se reabriron para o turismo. En ambos os casos a experiencia persoal da visita xira á volta das tecnoloxías e o saber facer, os edificios e os lugares industriais, as etapas económicas e sociais e a estética que crea a industrialización ou a perda definitiva da produción. Os territorios xogan un papel moi importante por seren o marco das distintas fases da Revolución Industrial, con sucesivas transformacións e declives que xeran vestixios e fitos patrimoniais que son testemuñas directas dun importante legado material.

Palabras clave: Turismo, industria, patrimonio industrial, territorio, paisaxe.

Abstract: Industrial landscapes and industries for tourism: heritage symbolism and territorial scope Industrial tourism responds to an emerging phenomenon relating to tourism activity surrounding industries that are still operating, with tours and visits designed to provide visitors with an insight into production processes. It also includes visits to sites with a long-standing in- 
dustrial tradition that have fallen into disuse and which have been reopened for tourists. In both cases the visit hinges on technologies and know-how, as well as the industrial buildings and sites themselves, considering social and economic cycles and the aesthetics generated by industrialisation or the ultimate loss of production activity. Territory plays a vital role in that it provides a setting for the various phases of the Industrial Revolution, marked by successive periods of transformation and decline, generating heritage-related remains and landmarks that are direct witnesses to a considerable material legacy.

Key words: Tourism, industry, industrial heritage, territory, landscape

\section{INTRODUCCIÓN}

Las expectativas de puesta en valor turístico del patrimonio industrial y su integración en los programas de turismo de masas son generales en toda Europa. Es cierto que el turismo ha experimentado un cambio hacia una demanda selectiva de nuevas formas que llenen el espacio de ocio de las sociedades desarrolladas, pero de momento se está aún lejos de que todos los vestigios musealizados o reinterpretados de la industrialización trasciendan la atención de un público especializado. Solo en algunos casos concretos la puesta en valor, como el gasómetro de Oberhausen en Alemania, el martillo pilón de Le Creusot en Francia, la antigua central eléctrica de Bankside Power Station en el Reino Unido o la mina de sal de Wieliczka en Polonia, ofrece la posibilidad de una integración turística en circuitos de gran alcance. No son las únicas experiencias en las que la recuperación ha concitado el interés de un público masivo, pero en la mayoría de las ocasiones las visitas son aún minoritarias y por debajo de las posibilidades reales como recurso de atracción turística.

Es necesario que la sociedad resuelva algunos interrogantes planteados en torno a la función del turismo en el patrimonio industrial. ¿Hay que llevar a cabo una valoración específica a través de un turismo cultural limitado a un público concreto, casi especialista? ¿Se debe potenciar un turismo de masas que procure integrar los testimonios industriales en la variada complejidad de una identidad regional? ¿Puede crearse, allí donde la industrialización ha marcado de manera más evidente todo un territorio, como en las cuencas siderúrgicas y mineras hoy inactivas, un "turismo de paisaje" como el desarrollado sobre otras bases en algunos lugares?

\section{PATRIMONIO INDUSTRIAL Y TERRITORIO}

Las tendencias actuales más desarrolladas en Europa favorecen un turismo industrial, menos especializado que el inicialmente desarrollado, en el que se integran otros valores culturales de carácter regional. La hipótesis de un turismo de paisaje o entorno ha resultado exitosa en zonas como la cuenca del Ruhr, marco de la puesta en escena de la denominada "ruta de la cultura industrial", pero resulta de difícil generalización en otros casos. 
El futuro se podría definir mediante el diseño de rutas o circuitos industriales apoyado sobre puntos ya marcados por uno o varios elementos patrimoniales ligados a un territorio. Este tipo de experiencia exige necesariamente tanto una intervención pública como inversiones privadas y ha contado desde la década de 1990 con el fomento de las instituciones europeas. El interés radica en la internacionalización que genera un turismo basado en estas prácticas, con itinerarios de gran alcance que afectan a varios países, como la ruta de la lana entre el Norte de Italia y Valonia.

Esta ruta, y otras más creadas en los últimos años en ámbitos tanto regionales como nacionales, se completa con otra más general de carácter europeo; es la ERIH, siglas inglesas de la que se conoce como "ruta europea de patrimonio industrial". Aprobada su creación por la Unión Europea en 1999, inició oficialmente su andadura en el año 2000. Esta ruta es una especie de red que enlaza una serie de hitos históricos importantes para potenciar antiguas regiones industriales desde el turismo. La primera fase se prolongó de 1999 a 2001, periodo en el cual se asociaron a la red varias regiones europeas al amparo de la iniciativa comunitaria INTERREG II C.

La creación concreta de la ruta ERIH tiene lugar en 2002 con la participación de las regiones alemanas del Sarre y Renania del Norte-Westfalia y otras de Gran Bretaña y Holanda. Es el núcleo originario de una gran ruta de patrimonio industrial que acabará enlazando con el tiempo aquellos puntos clave de la actividad industrial en nuestro continente, reconociendo sus características intrínsecas como base para potenciar el turismo industrial. El patrimonio de la industrialización se convierte, de esta forma, en elemento de integración europea.

La red se ha constituido mediante la participación de los lugares europeos más importantes y atractivos, denominados anchor points o puntos de referencia. Estos puntos quedan unidos por la idea de la trascendencia de su paisaje industrial, así como las regiones o zonas que se agreguen en un futuro. Esos anchor points representan el corazón del patrimonio industrial europeo y ya se están dotando de la necesaria infraestructura turística para su mejor conocimiento e interpretación.

El marketing de la ruta ERIH ofrece de manera adecuada los sitios a visitar, informa a los turistas sobre la red y coopera estrechamente con las organizaciones turísticas regionales, nacionales e internacionales. El éxito de los puntos de referencia está precisamente en la colaboración que se establece entre organismos diferentes a nivel local y en la imagen ofrecida de turismo de calidad, que toma como referencia los valores medioambientales que entrañan la recuperación y el reciclaje de las viejas arquitecturas industriales.

La red, en lugar de englobar a todas las regiones de industrialización tradicional del continente, agrupa a los lugares más representativos. Arrancando de Gran Bretaña, cuna de la Revolución Industrial, con sitios como Ironbridge, Manchester, el valle del río Derwent o Gales, la ruta llegará luego a Holanda, Bélgica, Luxemburgo, Norte de Francia (Pas-de-Calais, Lorena y Alsacia), Norte de España (País Vasco y Cataluña), Suiza, Norte de Italia (Piamonte, Lombardía y Véneto). Desde aquí se dirigirá a Austria, República Checa (Moravia), Polonia (Silesia), Finlandia (Häme), 
Suecia (Bergslagen) y Dinamarca (área metropolitana de Copenhague), para adentrarse posteriormente en Alemania (Renania del Norte-Westfalia), Sarre y cuenca del Ruhr). Estas tres últimas regiones son consideradas en la ruta como el corazón histórico de la industrialización europea.

El desarrollo de una ruta turística de esta índole conlleva fuertes inversiones en intervenciones de recuperación, adecuación y promoción. Las ventajas de tipo económico, social y territorial resultan evidentes aunque hay que considerar que no se deben de primar los cálculos de rentabilidad a corto plazo en este tipo de proyectos.

La vuelta a una especie de romanticismo aventurero, tan propio del siglo XIX, parece presidir el afán por descubrir en nuestros días los rasgos definitorios de los vestigios industriales. Considerados diferentes y poseedores de un exotismo incomparable, forman parte de la cultura material de comarcas, regiones y países que, al amparo de un cambio de tendencias en el turismo surgido tras la II Guerra Mundial, basado en el descanso de grandes masas de población cerca del mar, preside un nuevo turismo que nos aproxima a las improntas dejadas por la Revolución Industrial.

\section{FUTURO TURÍSTICO DEL PRESENTE Y DEL PASADO INDUSTRIAL}

El turismo practicado en torno a las industrias puede ser de dos tipos diferentes en función de los centros visitados:

El primero es el turismo industrial de tipo fabril o productivo. Consiste en la visita a las industrias aún en activo en donde se muestran las instalaciones de la empresa y la fabricación de un determinado producto. El interés es básicamente técnico y en estas visitas la maquinaria en uso se convierte en un motivo de especial atracción. Las formas que adopta este turismo fabril o productivo abarcan las jornadas de puertas abiertas, las visitas de empresa y los circuitos de turismo industrial.

Las jornadas de puertas abiertas son frecuentes y constituyen una estrategia promocional de la empresa que permite al público la toma de contacto con su actividad. Los visitantes conocen a los trabajadores y directivos y aprenden los aspectos más interesantes de la producción en el marco de una actividad relacional promovida directamente por la empresa para captar clientes potenciales y mostrarse más transparente. Es una ocasión que se aprovecha para exponer los productos fabricados a la venta sin intermediarios y en condiciones económicas generalmente ventajosas, todo ello si la naturaleza de los productos lo permite.

Las visitas de empresa forman parte de un programa instituido previamente y al margen de cualquier intervención turística de tipo profesional. Bajo la responsabilidad de un encargado, la empresa se deja descubrir por la población local o por los visitantes ocasionales. Estas visitas no se alejan demasiado de las jornadas de puertas abiertas y la única diferencia es que la operación no es excepcional.

El éxito es más importante en el caso de empresas destinadas a la elaboración de productos de consumo final, sobre todo en el ámbito agroalimentario. En el caso 
de las fábricas de productos semielaborados la situación es diferente. Algunas empresas de procedimientos técnicos complejos se benefician igualmente de una reputación que favorece las visitas, como las centrales hidroeléctricas, las industrias de montaje de automóviles o aviones, etc. En el año 2005 la fábrica Clément Ader, próxima a la ciudad francesa de Toulouse y vinculada al ensamblaje aeroespacial, recibió a más de 85.000 visitantes a pesar de carecer de cualquier valor patrimonial de tipo histórico.

Los circuitos de turismo industrial son promovidos por los organismos locales como instrumento de desarrollo económico. En estos circuitos se mezclan las visitas a los lugares más modernos con otros tradicionales, lo que permite obtener una idea global de la trayectoria industrial de la zona. El turista puede escoger las visitas que más le interesen y esto es precisamente lo que sucede con el programa de Turismo Industrial de la Oficina de Promoción Turística de Barcelona. Con uno de los patrimonios industriales más variados de España (antiguas fábricas, museos, minas, colonias industriales, almacenes, depósitos, hornos, bodegas...), se pueden organizar en torno a la ciudad de Barcelona diferentes recorridos para descubrir el pasado, el presente y el futuro de la tecnología y el trabajo. Por la proximidad a la gran zona turística de la Costa Brava, este programa ofrece un turismo alternativo pero complementario del tradicional de sol y playa. El número de visitas global avala el éxito alcanzado por la promoción. 
Figura 1. Tipos y formas de turismo industrial

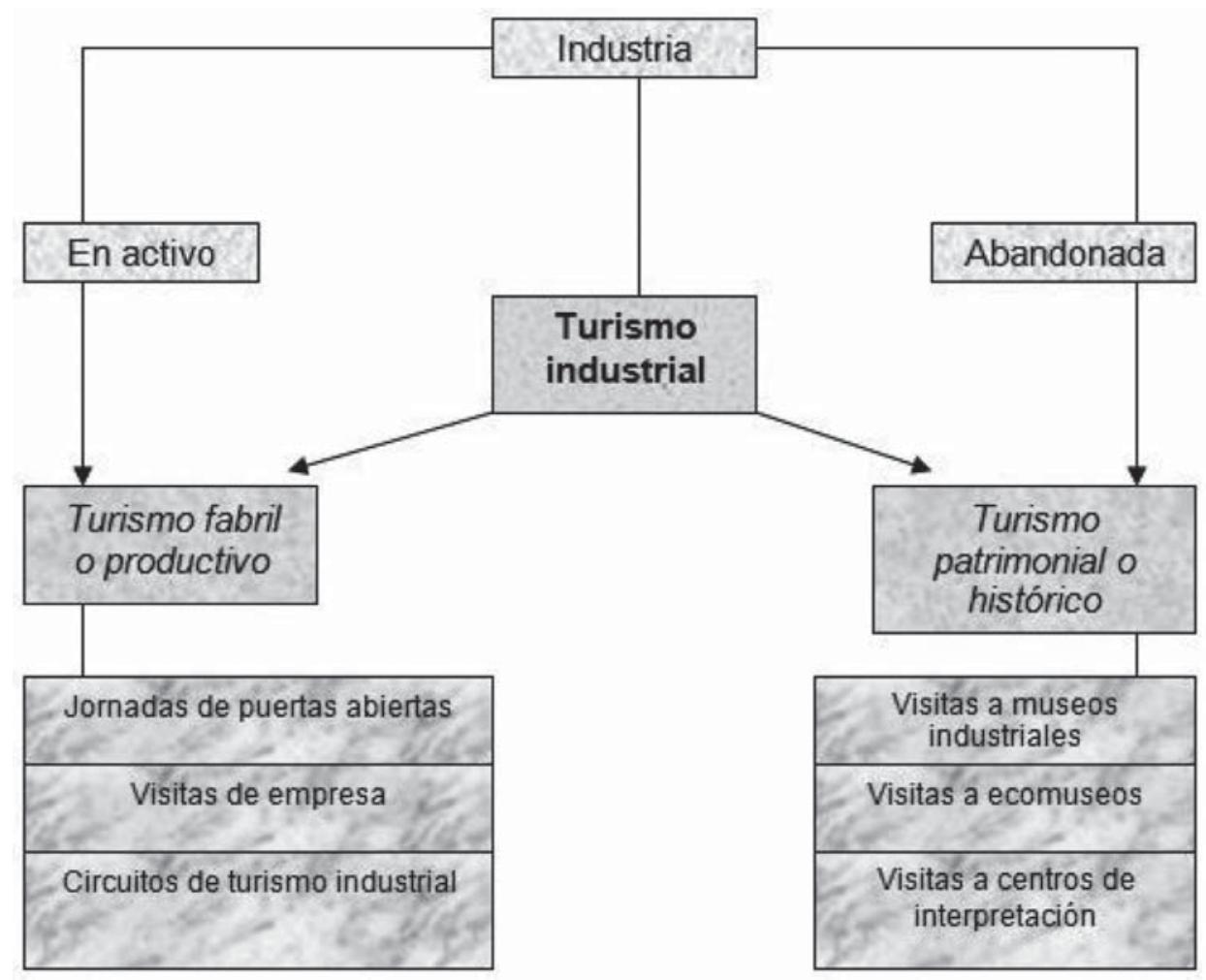

El segundo es el turismo industrial de tipo patrimonial o histórico. En este caso las visitas se centran en fábricas abandonadas con reutilización museística o de algún centro artístico o interpretativo. En este turismo industrial el interés es básicamente cultural y toma como reclamo las piezas conservadas, como máquinas de vapor, hornos, chimeneas, etc., y la estética de la arquitectura industrial reutilizada. El territorio circundante juega un papel fundamental, ya que aporta uno de los elementos más importantes para la caracterización social y económica de la industrialización. Las formas que adopta este tipo de turismo industrial son las visitas a los museos industriales, ecomuseos y centros de interpretación.

Las visitas a los museos industriales persiguen la aproximación al pasado técnico, productivo, arquitectónico, material y laboral de nuestra sociedad. Estos museos ayudan a identificar y aplicar estrategias que enlazan la desindustrialización con los acervos culturales y su comprensión por el público en general. 
Figura 2. Interior musealizado de la fábrica de Boinas La Encartada (Balmaseda, Vizcaya)

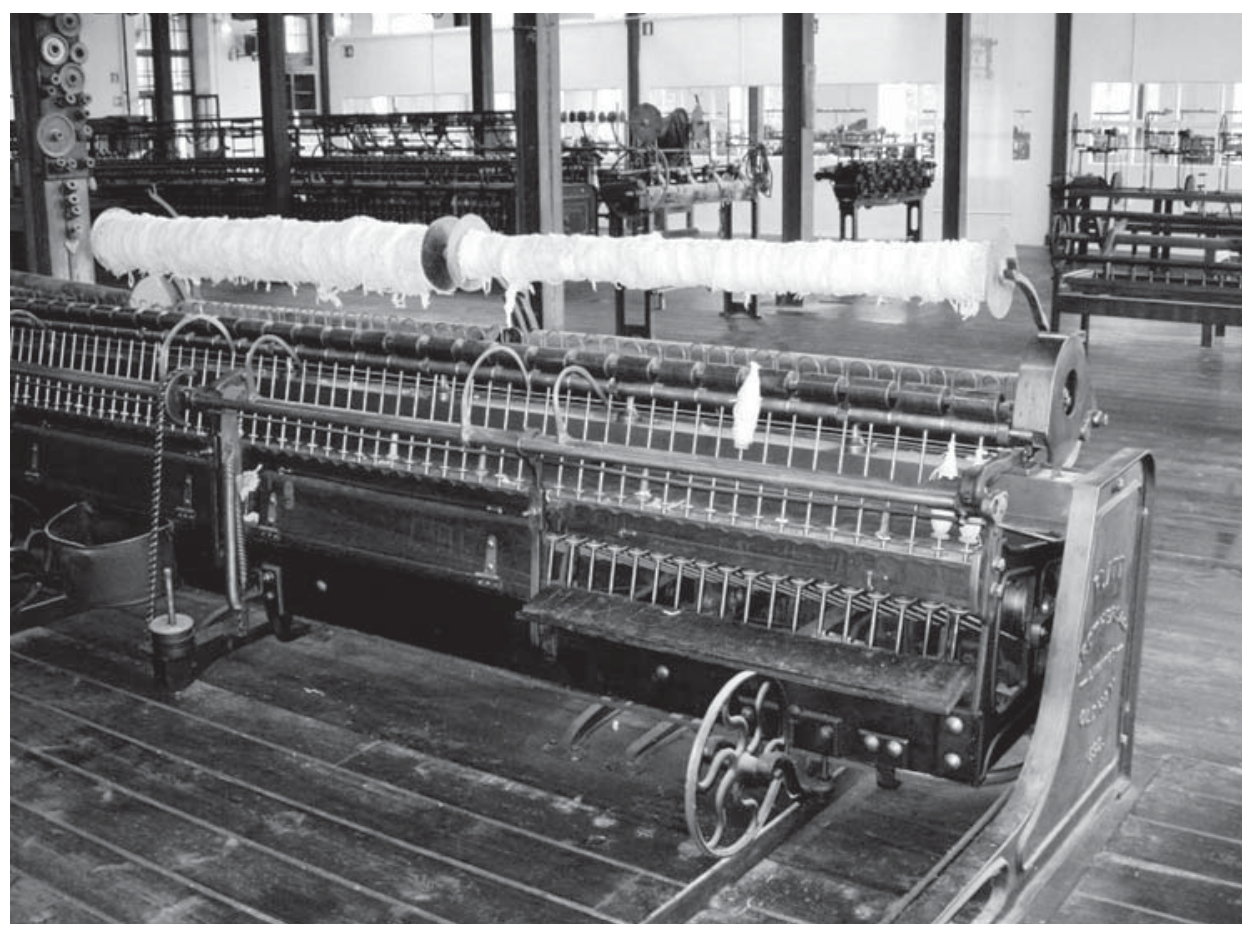

La selección de los testimonios materiales a preservar es muy importante debido al carácter homogeneizador de la industrialización en las formas de vida y trabajo y en el uso de herramientas. Por esta razón pocas veces se considera al patrimonio industrial como singular, a pesar de las numerosas excepciones y funciones de la implantación e impacto territorial de las industrias. La musealización debe interpretar correctamente las particularidades ofrecidas por este patrimonio a nivel local y tomar la suficiente perspectiva como para conferir relevancia nacional e internacional.

Cuando se musealizan amplios testimonios industriales de un territorio más o menos extenso se habla de ecomuseo. La significación de este concepto deriva de sus vinculaciones con el desarrollo territorial al poner en nuevo uso un número generalmente elevado de instalaciones en una misma región.

La zona minera de Riotinto, para la que la Consejería de Cultura de Andalucía ha incoado recientemente el procedimiento para su inscripción como Bien de Interés Cultural con la categoría de Zona Patrimonial, está integrada por un conjunto de bienes que son testimonio de las diversas culturas y sociedades mineras que han ocupado este territorio, en los términos municipales onubenses de Minas de Riotinto, Nerva y, puntualmente, El Campillo.

El área se caracteriza por constituir un paraje natural fuertemente antropizado con numerosos elementos del desarrollo de la minería a lo largo de la historia, ele- 
mentos distintivos y específicos que, en conjunto, conforman un patrimonio único con valores tan relevantes como los que presenta el río Tinto, la corta Atalaya y el ferrocarril minero, entre otros. En este sentido, la zona es uno de los mejores exponentes para comprender la evolución histórica de las explotaciones mineras en el Suroeste europeo.

Las minas forman parte de una amplia masa de piritas de hierro y cobre. $\mathrm{Su}$ historia es bastante antigua y se traslada a las primeras civilizaciones organizadas en el Calcolítico. Pero el desarrollo a mayor escala se produjo con los romanos, que introdujeron nuevas técnicas con las que conseguir la intensificación de los trabajos mineros. Los restos de escorias encontrados indican una gran actividad minera en esta época. Durante la Edad Media, la minería extractiva decayó por completo y los árabes solo obtuvieron de las minas algunos tintes con fines medicinales. El largo paréntesis de abandono quedó roto en el siglo XVIII, cuando el sueco Liebert Wolters compró los yacimientos y reinició las tareas de explotación.

La zona minera experimentó en el siglo XIX el momento de mayor apogeo industrial, demográfico y económico. En 1873 un consorcio británico compró las minas al Estado y fundó la Río Tinto Company Limited (en adelante, RC Ltd.) A partir de entonces se abrieron cortas de explotación y se desarrolló la minería interior. En 1888, las calcinaciones de minerales al aire libre o "teleras" propiciaron la primera manifestación severa de impacto ambiental en la zona.

Figura 3. Paisaje minero de Riotinto (Huelva)

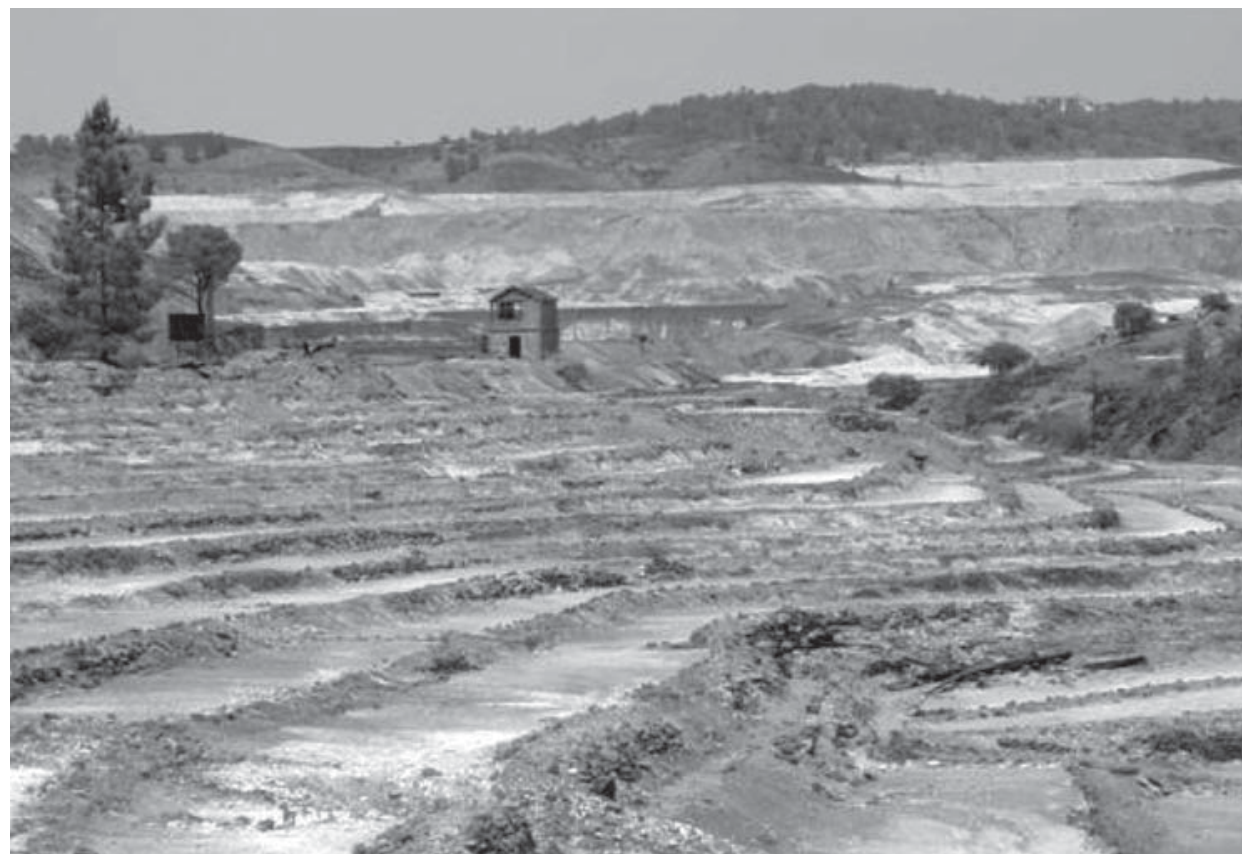


Un hecho importante fue la inauguración en 1875 de la línea de ferrocarril entre Riotinto y Huelva para el transporte de minerales hasta el muelle de Riotinto, en el puerto de la capital. El muelle y el embarcadero de mineral son, desde su construcción entre 1874 y 1876, uno de los rasgos más emblemáticos de Huelva y forman parte de un conjunto de ambiciosas iniciativas urbanísticas de la RC Ltd. que contribuyeron a definir el paisaje urbano de ciertos barrios de la ciudad. El embarcadero es una larga plataforma serpenteante de 1.165 metros de longitud que se adentra en la ría del Odiel. Diseñado por los ingenieros británicos Bruce y Gibson, sorprendió desde un principio por su sistema de cimentación.

El muelle-embarcadero, que dejó de utilizarse en 1975, es una de las obras de mayor relevancia de la compañía minera y fue determinante, junto a la construcción del ferrocarril hacia Riotinto y los nuevos métodos de explotación minera, para explicar el enorme éxito de la compañía británica en el siglo XIX y su influencia social y económica en la provincia. A principios del siglo $\mathrm{XX}$, la $R C L t d$. ya se consolidó como la empresa privada con más mano de obra de todo el país, alcanzando casi los 20.000 empleados en total. Esto refleja el extraordinario negocio que supuso la minería en esta parte de Andalucía.

El tráfico de mineral del ferrocarril de Riotinto fue posible gracias a la existencia de 1.300 vagones y 2.000 vagonetas de mina, además de 143 locomotoras de vapor y 7 eléctricas. Las locomotoras de vapor eran de diez modelos diferentes y todas, con la única excepción de seis, fueron fabricadas en Inglaterra entre 1874 y 1954.

El ferrocarril minero siguió funcionando durante todo el periodo en el que la compañía británica fue propietaria de las minas de Riotinto, y aún después de pasar a manos españolas en el año 1954. La pérdida de su funcionalidad vino a partir de 1964, cuando se construyó el Polo Químico de Huelva. Desde entonces, y dado que el mineral ya no se embarcaba hacia Inglaterra, resultó más rentable transportarlo en camiones. En 1975 dejó de funcionar el muelle y el último tren en bajar por la vía del ferrocarril lo hizo en 1984. Hoy se utiliza la línea con fines exclusivamente turísticos y en un tramo de unos $25 \mathrm{~km}$.

Entre los bienes de patrimonio industrial destacan algunas piezas ferroviarias que se remontan a la introducción de la Revolución Industrial en España. Destaca una serie amplia de locomotoras a vapor, en la que se encuentran algunos elementos tan interesantes como la locomotora-grúa 150 depositada en el Museo Minero. La zona contiene también construcciones fundamentales en los procesados del mineral o estructuras relacionadas con la tostación, como las teleras, edificaciones fabriles como la Lavadora, el plano inclinado de Tío Jaime, los talleres de reparación o la fundición de piritas. Entre las infraestructuras mineras destacan los malacates de los pozos Alfredo y Rotilio y el edificio depósito de Bomba Cornish. Las estaciones de ferrocarril del Valle de Minas de Riotinto y la de Nerva forman parte también de este patrimonio minero-industrial.

Los testimonios arquitectónicos de carácter civil y la disposición urbanística marcan una profunda diferencia entre la comarca minera y el resto de la región, 
consecuencia de la imposición de unos sistemas constructivos concretos y de una ideología propia de las sociedades mineras inglesas. Uno de los elementos protegidos es la barriada de Bellavista, donde destacan, dentro de los bienes inmuebles que lo configuran, la capilla anglicana, la casa-consejo y el cementerio protestante. Otro elemento bien definido es la trama urbana de El Valle, diseñada por la compañía británica para alojar a los trabajadores que hasta entonces vivían en el antiguo lugar denominado La Mina, destruido por la compañía para extender la explotación minera del subsuelo. El nuevo pueblo presenta un esquema urbanístico y arquitectónico propio de los campamentos mineros, con un plano en cuadrícula y viviendas con un claro aire victoriano. Destacan por su proyección arquitectónica el antiguo hospital inglés, adaptado en la actualidad para Museo Minero, la casa-dirección, hoy sede de distintas entidades locales, o la antigua agencia de trabajo de la compañía minera, que contiene el archivo histórico de la Fundación Riotinto.

La dominación colonial minera introdujo cambios culturales que, fruto de la forma de explotación y trabajo, incidieron en las mentalidades y en las relaciones laborales y sociales; se manifiestan en un amplio abanico de bienes intangibles heredados de una manera de vida basada en las normas y dictados de las compañías mineras inglesas.

El paisaje de la comarca es espectacular, por la entidad y proporciones de las explotaciones: cerros convertidos en profundas cavidades, colinas artificiales de escorias o de rocas sobrantes, coloraciones rojizas, ocres, amarillas, moradas y verdeazuladas que transmiten de forma mágica el impacto de la mano del hombre sobre la naturaleza a lo largo del tiempo. El medio natural así transformado adquiere una clara dimensión de patrimonio cultural. Los espacios que mejor detallan la actividad minera son Peña del Hierro, Corta Atalaya, Cerro Colorado y las galerías romanas de Corta Dehesa.

A finales de los años ochenta se crea la Fundación Riotinto con un triple objetivo: estudiar e investigar la historia de la minería y de la metalurgia; conservar y restaurar el conjunto mediante la constitución de un Parque Minero; y difundir los valores histórico-culturales que contiene la zona. La creación del citado parque con fines culturales, turísticos y recreativos está siendo un factor clave de recuperación y puesta en valor de su patrimonio, así como de dinamización económica en esta parte oriental de la provincia de Huelva. En el año 2010 el número total de visitantes se aproximó a la cifra de 80.000 .

Las visitas a los centros de interpretación se enmarcan en un turismo de carácter cultural cuyo objetivo es explicar el funcionamiento de las viejas fábricas reviviendo su pasado productivo. Las demostraciones son muy didácticas, sirven para todos los públicos y uno de los tipos más frecuentes de visitas son los grupos escolares. Suelen contar estos centros con materiales publicados en forma de libros, cuadernos de actividades y videos que completan las explicaciones de los paneles explicativos y del personal encargado. 
Los dos tipos de turismo industrial constituyen un vector de mediación entre la fábrica y el público que permite a los visitantes descubrir el valor cultural de las actividades industriales en funcionamiento o ya abandonadas, en este último caso incorporando una perspectiva histórica que hace comprensible la evolución de las técnicas y los lugares. Ambos han sido más importantes en los países del Norte de Europa que en los del Sur. En Alemania, Suecia, Finlandia, Reino Unido, Bélgica... se han acogido con verdadero entusiasmo las posibilidades turísticas ofrecidas por el patrimonio industrial; en España, Francia, Italia, Grecia o Portugal el interés ha sido más tardío como consecuencia del mayor peso del patrimonio histórico-artístico.

Cuadro 1: Algunas cifras de turismo industrial de tipo patrimonial en Europa

\begin{tabular}{|c|c|c|c|}
\hline Centro patrimonial & Localidad/región & País & $\mathrm{N}^{\mathrm{o}}$ visitas/año \\
\hline Parque Minero & Riotinto & España & 80.000 \\
\hline Parque Minero & Almadén & España & 15.000 \\
\hline Molino Papelero & Capellades & España & 31.000 \\
\hline Museo Minero & Cercs & España & 29.000 \\
\hline $\begin{array}{c}\text { Museu de la Ciència i } \\
\text { Tècnica } \\
\text { Parque Minero }\end{array}$ & $\begin{array}{c}\text { Tarrasa } \\
\text { La Unión }\end{array}$ & $\begin{array}{l}\text { España } \\
\text { España }\end{array}$ & $\begin{array}{l}90.000 \\
15.000\end{array}$ \\
\hline Halle Tony Garnier & Lyon & Francia & 500.000 \\
\hline Centro Minero & Lewarde & Francia & 250.000 \\
\hline $\begin{array}{c}\text { Parque Minero San } \\
\text { Silvestro }\end{array}$ & Campiglia & Italia & 30.000 \\
\hline Mina de Sal & Wieliczka & Polonia & 800.000 \\
\hline Ironbridge & Telford & Reino Unido & 300.000 \\
\hline New Lanark & Lanark & Reino Unido & 400.000 \\
\hline Ecomuseo de Bergslagen & Bergslagen & Suecia & 450.000 \\
\hline
\end{tabular}

Fuente: Museos y centros de interpretación respectivos y elaboración propia.

En todos los casos, los vestigios recuperados de la industrialización están creando ya unos flujos de visitas realmente importantes en todos los países y conforman 
una oferta cultural en continuo crecimiento que logra incorporar a los circuitos culturales muchas regiones sin tradición turística previa.

La mina de sal de Wieliczka constituye un caso paradigmático por haber sido el primer elemento industrial en ser declarado patrimonio de la humanidad por la UNESCO en el año 1978. Es el único lugar del mundo donde la actividad minera ha continuado desde la Edad Media. Ello permite conocer la evolución de las técnicas extractivas y aproximarse al impacto económico de la actividad en la región. En otros tiempos la sal fue usada como medio de pago, reemplazando incluso a la acuñación metálica de moneda. Su explotación acabó siendo monopolio real, lo mismo que la distribución. La sal se convirtió en un instrumento de gobierno y en algunos momentos llegó a asegurar el $30 \%$ de todos los ingresos del Estado. Durante el siglo XVI la mina se convirtió en uno de los negocios más rentables de Europa.

La visita turística actual incluye solo una pequeña parte de toda la mina y dura aproximadamente dos horas y media, alcanzándose una profundidad máxima de 130 metros. Uno de los mayores atractivos es la visita a una cámara tallada enteramente en la sal, con abundancia de esculturas, bajorrelieves y candelabros hechos con cristales de sal. A lo largo del recorrido se pueden conocer diferentes máquinas y equipos, auténticos testimonios de los viejos trabajos mineros, una sala de teatro y otra de ópera habilitadas en el conjunto subterráneo.

La mina y su laberíntica red de cámaras y pasadizos han despertado siempre un gran interés, ya desde el siglo XIV con las visitas de diferentes personalidades de la corte real. La situación próxima a Cracovia ha favorecido el desarrollo del turismo. A comienzos del siglo XIX se habilitaron varias cámaras históricas del primer nivel para las visitas y la ruta luego se fue ampliando con nuevas salas en los niveles dos y tres y nuevas atracciones. Desde principios del siglo XX existían ya campañas turísticas organizadas para mostrar el interior de la mina, quedando interrumpidas durante la ocupación nazi.

El turismo se reanudó a partir de 1945: si en ese año los visitantes fueron 10.000, en 1955 el número se elevó a 200.000 y a mediados de la década de 1970 los turistas superaban la cifra de los 750.000 anuales. Actualmente la mina acoge a más de 800.000 visitas al año y se ha convertido en uno de los mayores atractivos turísticos de toda Polonia.

Otra experiencia que sirve de referencia europea es New Lanark, en el Reino Unido. Este establecimiento, fundado en 1785, fue uno de los primeros en el mundo dedicados a la manufactura del algodón. Se usaba el agua como fuente de energía, tomada de las cascadas del río Clyde para mover una maquinaria diseñada por Richard Arkwright, el inventor del telar hidráulico. En torno a los telares mecánicos se construyó un poblado que alcanzó fama internacional a principios del siglo XIX como comunidad filantrópica bajo la dirección de Robert Owen. La pieza central de su experimento era la educación como llave para conseguir una sociedad mejor y más justa. 
En 1820 la comunidad logró su cenit demográfico con 2.500 habitantes. Tras la partida de Owen a América en 1825, los molinos de algodón de New Lanark continuaron su producción. A finales del siglo XIX las ruedas de agua se sustituyeron por turbinas hidráulicas y desde 1898 los propios molinos comenzaron a generar energía hidroeléctrica. A partir de ese momento, la electricidad dejó de ser utilizada solo para la iluminación y se convirtió en la fuente energética principal del complejo hasta su cierre en 1968, casi doscientos años después de su fundación.

Se perdieron entonces 350 puestos de trabajo, comenzó el abandono de los edificios y la zona inició un declive espectacular en paralelo a la destrucción de las viejas construcciones. En 1972 comenzaron los estudios para examinar las opciones de futuro para New Lanark: tras descartarse la demolición parcial del pueblo se decidió su restauración y recuperación total. En 1973 todos los edificios fueron catalogados con la más alta figura de protección en Escocia y el pueblo fue designado como Área Excepcional de Conservación en reconocimiento a su especial significado en la historia económica y social contemporánea. Se creó un consorcio para la restauración de los edificios industriales, idea por entonces poco extendida y considerada por muchos como excéntrica y extraña.

El turismo se convirtió en la apuesta para el mantenimiento de la localidad como comunidad vinculada al alojamiento, la recepción de visitantes, la producción hidroeléctrica y el alquiler de locales comerciales. En la actualidad, casi 200 personas viven en el poblado.

El consorcio de New Lanark ha creado un centro de visitantes y varias exposiciones diferentes en donde se relatan las condiciones de vida y trabajo, el sistema de educación de Robert Owen y la rehabilitación efectuada en el conjunto. El desarrollo del alojamiento para visitantes fue un aspecto fundamental: en 1994 se abrió un albergue y en 1998 se inauguró el New Lanark Mill Hotel en el molino número 1. En New Lanark, el turismo es la más importante actividad generadora de ingresos y actualmente la localidad atrae a unos 400.000 visitantes al año. El carácter patrimonial del enclave y su significado internacional fue reconocido en el año 2001 al ser inscrito en la lista de la UNESCO de patrimonio de la humanidad.

\section{CONCLUSIONES}

Los ejemplos comentados muestran cómo el turismo industrial, una de las tipologías turísticas más recientes, ha acabado por adquirir un protagonismo al margen de toda duda al contribuir a la construcción de un futuro prometedor y ofrecer nuevas perspectivas de empleo para la población local. Las visitas a las actuales fábricas o la reutilización turística de las viejas edificaciones industriales no solo tiene una dimensión socioeconómica: las nuevas formas de turismo están también vinculadas a la ecología, y el reciclaje de las construcciones industriales abandonadas para nuevos usos tiene, en principio, una importancia ambiental perdurable. Además no son 
pocos los que piensan que su utilización turística engendra unos efectos ecológicos positivos debido a que contribuye a reducir la presión sobre el espacio natural.

El turismo industrial es una modalidad que busca un "arte" alejado del tradicional en museos sin vitrinas estancas ni objetos capturados, permitiendo una mayor participación al visitante, que interactúa con el contenido expositivo de una forma clara, amena y muy didáctica. Se relaciona, además, con las propias vivencias personales de una gran parte de los turistas, para los que la producción industrial no es algo alejado y distante. De hecho, en torno al $30 \%$ de los 300.000 visitantes anuales de Ironbridge son personas jubiladas, a lo que hay que sumar el $45 \%$ de profesionales y el $25 \%$ de visitas organizadas en grupos.

Más allá del objetivo de conocer un determinado proceso productivo en una fábrica aún en funcionamiento, las motivaciones que impulsan al turista a realizar la visita a un lugar de vieja producción son diversas: búsqueda del significado histórico y arqueológico, conocimiento de un medio extraño y totalmente distinto del que existe en la ciudad, interés por comprender algunos funcionamientos técnicos en desuso, profundización nostálgica en una época y unas formas de vida ya perdidas, etc. El turismo industrial de tipo patrimonial vincula al visitante con el pasado de la Revolución Industrial, a través del conocimiento directo de los vestigios, museos, centros culturales e itinerarios existentes en las áreas marcadas por los avances técnicos y productivos de los dos últimos siglos. Aparece, de esta forma, una nueva Geografía del turismo preocupada por el simbolismo de los monumentos industriales y los territorios de la industria, en definitiva, por un patrimonio cultural de indudable interés turístico y recurso para un desarrollo sostenible respetuoso con los testimonios de un pasado espléndido.

\section{BIBLIOGRAFÍA}

AA.VV. (2011): 100 elementos del patrimonio industrial en España, Gijón, CICEES. AGUILAR, I. (1998): Arquitectura industrial. Concepto, método y fuentes. Valencia, Diputación de Valencia.

AGUILAR, I. (2003): "Patrimonio industrial. Aprovechamiento cultural y reutilización”. Estructuras y paisajes industriales, Gijón, INCUNA, p. 41-61.

ALFREY, J. (1992): The industrial heritage: managing resources and uses. Londres, Routledge.

ÁLVAREZ, M. A. (2001): "Patrimonio industrial, identidad cultural y sostenibilidad". Arqueología industrial, patrimonio y turismo cultural, Gijón, INCUNA, p. 13-31.

ÁlVAREZ, M. A. (2007): Arqueología Industrial. El pasado por venir. Gijón, CICEES, Colección 'La herencia recuperada'.

ÁlVAREZ, M. A. (2007): “Tecnoturismo y turismo industrial”, Ábaco. Revista de Cultura y Ciencias Sociales, 54, p. 21-37. 
ÁlVAREZ, M. A. y GONZÁLEZ, V. (2002): "Mapa de recursos del patrimonio industrial". Patrimonio industrial: lugares de la memoria, Gijón, INCUNA, p. 87-108.

ÁlVArEZ, M. A., FElGuEroso, R. y SUÁrEZ, F. (2003): "Industrias culturales y patrimonio industrial”. Estructuras y paisajes industriales, Gijón, INCUNA, p. 15-39.

ANDRIEUX, J.-Y. (1992): Le patrimoine industriel. París, Presses Universitaires de France, Colección 'Qué sais-je?'.

BAYÓ SOLER, C. (2003): "Paisaje industrial y modernista de Terrassa. Del paisaje industrial al recorrido turístico". Estructuras y paisajes industriales, Gijón, INCUNA, p. 133-139.

BÉGHAIN, P. (1998): Le patrimoine: culture et lien social. París, Presses de la Fondation Nationale des Sciences Politiques, Colección 'La Bibliothèque du citoyen'.

BENITO, P. (1997): "Dinamización del territorio y patrimonio industrial”. Polígonos, 7 , p. 123-131.

BENITO, P. (2002): "Patrimonio industrial y cultura del territorio". Boletín de la Asociación de Geógrafos Españoles, 34, p. 213-227.

BENITO, P. (2003): "El patrimonio industrial a través de la prensa". Estructura y paisajes industriales, Gijón, INCUNA, p. 145-155.

BERGERON, L. (2002): “El patrimonio industrial, ¿qué hacer?”. Patrimonio industrial: lugares de la memoria, Gijón, INCUNA, p. 11-16.

BERGERON, L. (2003): "La valorización turística del patrimonio industrial". Estructuras y paisajes industriales, Gijón, INCUNA, p. 9-13.

BERGERON, L. y DOREL-FERRÉ, G. (1996): Le patrimoine industriel: un nouveau territoire. París, Éditions Liris.

BUTLER, R. W. (1999): "Sustainable tourism: a state-of-the art review". Tourism Geographies, 1, p. 7-25.

CAÑIZARES, M. C. (2008): "El atractivo turístico de una de las minas de mercurio más importantes del mundo: el Parque Minero de Almadén (Ciudad Real)", Cuadernos de Turismo, 21, p. 9-31.

CAÑIZARES, M. C. (2011): "Protección y defensa del patrimonio minero en España”, Scripta Nova, XV, 361 (http://www.ub.es/geocrit/sn/sn-361.htm).

CAPEL, H. (1996): "La rehabilitación y el uso del patrimonio histórico industrial". Documents d'Analisi Geogràfica, 29, p. 19-50.

CASANELLES, E. (1998): "Recuperación y uso del patrimonio industrial”. Ábaco. Revista de Ciencias Sociales, 19, p. 11-18.

CASANELLES, E. y FERNÁNDEZ, M. (1994): "Un modelo para trabajar: el patrimonio industrial”. El patrimonio histórico-artístico, Barcelona, Graó Educación.

DAMBRON, P. (2004): Patrimoine industriel et développement local. París, Éditions Jean Delaville. 
DICKSON, K. (2008): "Finding new uses for redundant industrial buildings, and working with the community to deliver local aspirations". Comunicación presentada en el Third European Industrial and Technical Heritage Weekend, Barcelona-Tarrasa, 24-26 de Octubre.

DOREL-FERRÉ, G. y FERRIOT, D. (2004): "Itinerarios y rutas del patrimonio industrial en Francia”. Rutas culturales y turísticas del patrimonio industrial, Gijón, INCUNA, p. 11-23.

EBERT, W. (2003): "ERIH, ruta europea de patrimonio industrial". Estructuras y paisajes industriales, Gijón, INCUNA, p. 73-78.

EDWARDS, J. A. y LLURDÉS, J. C. (1996): "Mines and quarries: industrial heritage tourism". Annals of Tourism Research, 23, p. 341-363.

FERNÁNDEZ G. y GUZMÁN, A. (2004): "El patrimonio industrial como recurso para crear rutas turísticas: algunas propuestas en Argentina". Caderno Virtual de Turismo, 4, p. 57-68.

FERNÁNDEZ DE PAZ, E. (2006): "De tesoro ilustrado a recurso turístico: el cambiante significado del patrimonio cultural". Pasos. Revista de Turismo y Patrimonio Cultural, vol. 4, p. 1-12.

FILIPE, G. (2003): "Patrimonio industrial, experiencias museológicas y proyectos de intervención en el territorio". Estructuras y paisajes industriales, Gijón, INCUNA, p. 79-87.

FRENCESCUTTI, P. (1993): "Recuperación de edificios industriales: tesoros fabriles". Revista del Ministerio de Obras Públicas y Transportes, 409, p. 90-95.

GÓMEZ, J. (2002): "Patrimonio industrial y turismo industrial". Gestión del Patrimonio Industrial en la Europa del siglo XXI, Bilbao, Congreso Vasco de Patrimonio Industrial, p. 215-221.

GONZÁLEZ, A. (2005): "El patrimonio industrial y las dificultades para su recuperación". DYNA, LXXX, p. 19-21.

GUZMÁN, A. y FERNÁNDEZ, G. (2003): "El patrimonio industrial desde perspectivas multidisciplinarias”. Biblio 3 W. Revista bibliográfica de Geografía y Ciencias Sociales, 480.

HOSPERS, G.-J. (2002): "Industrial heritage tourism and regional restructuring in the European Union”. European Planning Studies, 10, p. 397-404.

JONES, C. y MUNDAY, M. (2001): "Blaenavon and United Nations World Heritage Site Status: Is Conservation of Industrial Heritage a Road to Local Economic Development?” Regional Studies, 35, p. 585-590.

JANSEN-VERBEKE, M. (1999): "Industrial Heritage: a Nexus for Sustainable Tourism Development”. Tourism Geographies, 1, p. 70-85.

LLURDÉS, J. C. (1994): "El turismo industrial y la estética de los paisajes en declive". Estudios Turísticos, 121, p. 91-107.

MAGÁN, J. M. (2005): "El patrimonio industrial: el gran olvidado en la legislación española sobre bienes culturales". Didáctica e interpretación del patrimonio industrial, Gijón, INCUNA, p. 107-116. 
McNULTY, R. H. (1985): "Revitalizing Industrial Cities through Cultural Tourism". International Journal of Environmental Studies, 25, p. 225-228.

PARDO, C. J. (2004): "La reutilización del patrimonio industrial como recurso turístico. Aproximación geográfica al turismo industrial”. Treballs de la Societat Catalana de Geografia, 57, p. 7-32.

PARDO, C. J. (2006): “Territorios de la industria, turismo industrial y desarrollo territorial”. LACOSTA, A. (Coord.): Turismo y cambio territorial: ¿eclosión, aceleración, desbordamiento?, Zaragoza, Prensas Universitarias de Zaragoza, p. 243-253.

PARDO, C. J. (2008): Turismo y patrimonio industrial. Un análisis desde la perspectiva territorial. Madrid, Editorial Síntesis, Colección 'Gestión Turística'.

PARDO, C. J. (2008): "Restoration and new uses for the industrial heritage of Madrid”. Industrial Patrimony, 20, p. 77-92.

PARDO, C. J. (2008): “Estrategias de ordenación y gestión urbana del patrimonio industrial en España”. Ciudad y Territorio. Estudios Territoriales, 157, p. 473498.

PARDO, C. J. (2010): "El patrimonio industrial en España: análisis turístico y significado territorial de algunos proyectos de recuperación”, Boletín de la Asociación de Geógrafos Españoles, 53, p. 239-264.

PÉREZ, L. y PARRA, C. (2004): "Paisajes culturales: el parque patrimonial como instrumento de revalorización y revitalización del territorio". Teoría, 13, p. 9-24.

PRENTICE, R. C., WITT, S. F. y HAMER, C. (1998): “Tourism as Experience: the Case of Heritage Parks". Annals of Tourism Research, 25, p. 1-24.

QUIVIK, F. L. (2000): "Landscapes as Industrial Artifacts: Lessons from Environmental History". The Journal of the Society for Industrial Archeology, 26, p. 55-64.

SABATÉ, J. (2004): "De la preservación del patrimonio a la ordenación del paisaje". Urbano, 10, p. 42-49.

SOBRINO, J. (1998): "La arquitectura industrial: de sala de máquinas a caja de sorpresas". Ábaco, 19, p. 19-28.

STRATTON, M. (2000): Industrial buildings: conservation and regeneration. Londres, E. \& FN. Spon.

VALENZUELA, M., PALACIOS, A. J. e HIDALGO, C. (2008): “La valorización turística del patrimonio minero en entornos rurales desfavorecidos. Actores y experiencias". Cuadernos de Turismo, 22, p. 231-260. 
